\title{
Analysis on the Stock Value of United Rentals, Inc. During COVID-19 -- Based on the Theory of Value Investment
}

\author{
Yuejia $\mathrm{Li}^{1, *},{ }^{\dagger}$, Haoxing Deng ${ }^{2, \dagger}$ and Mingjing $\mathrm{Xie}^{3, \dagger}$ \\ ${ }^{1}$ School of Busniess Administration, San Diego State University, San Diego, CA 92182, America. \\ ${ }^{2}$ School of Investment, Chengdu University of Technology, Chengdu, Sichuan 610059, China. \\ ${ }^{3}$ School of Foreign Languages, Hainan University, Haikou, Hainan 570100, China. \\ *Corresponding author. Email: yli16@sdsu.edu \\ ${ }^{\dagger}$ These authors contributed equally.
}

\begin{abstract}
With the development of the world economy, investors and the stock market are growing. How to judge whether a stock has invest value becomes the main problem for investors to consider. In this paper, we focus on the leasing market due to its great development potential. This study discusses how to choose the most suitable investment object for investors among a wide array of leasing companies. Our paper uses the theory of value investment, and we select United Rentals as the research object to calculate and analyse its fundamentals. Then, we compare United Rentals with other companies in the same industry to judge its value investment and give investors some suggestions. United Rentals not only have the largest market share in North American but also have the characteristics of high profitability, high risk resistance, and low prices. This study enables investors to have a better understanding of the value of United Rentals, especially in the impact of the COVID-19 phase.
\end{abstract}

Keywords: COVID-19, value investment, leasing industry, United Rentals, value evaluation

\section{INTRODUCTION}

The sudden attack of COVID-19 in 2019 has a huge impact on the world economy, and the rental industry has also adversely affected in many ways. According to statistics from Joint Research and Development Center for Leasing, in the first half of 2020, the total leasing business in the United States was $\$ 979$ billion, down 3.1\% from the previous year's $\$ 1,010$ billion [1]. However, North America still ranks first in the world, accounting for about $24.5 \%$ of the world's total business. This means that even if the North American rental industry is adversely affected by the decline in sales, the United States, the world's largest rental market, still has a lot of room for growth. Compared with other aircraft, ship and vehicle leasing businesses, which are considerably affected by COVID-19, equipment rental still occupies the first place in the major market of international leasing business, accounting for about $20.8 \%$. The above indicator is that the development of equipment leasing is relatively stable, with limited impact from the COVID-19.
The topic of this paper is to analyze the Rental market in the United States under the background of COVID-19, the value investment strategy of United Rentals, Inc. with the first market share, and then make recommendations to investors. We try to use both theoretical and practical types of articles as a reference for our paper.

Sun sorted out the construction machinery data of the United States, and the data showed that the United States had already been the most developed country in the leasing industry in the world at that time [2]. Therefore, the favorable development of construction machinery energy in the United States was analyzed in many aspects. According to the Report on the Development of Finance Leasing Industry in the First Half of 2020 issued by the Joint Research and Development Center for Leasing(2020), the United States is still the world's largest leasing market with the largest market share. This demonstrates that the United States in these ten years has been exerting its own advantageous environment and dominant position to maintain its core position in the leasing industry. Li 
stated that each aspect of United Rentals' financial statement data combined with the company's operating and leasing environment to analyze so as to have a comprehensive and careful analysis of the situation [3].

Graham and Dodd mentioned the concept of value investment in their book and believed that correct investment decisions could be made through the analysis of a company's financial situation [4]. Berk and Demarz systematically discussed and analyzed the value investing, and also systematically explained how to analyze the value of a company from financial statements [5]. Sun analyzed the common stock pricing models of listed companies from the perspective of value investment and emphasized the practical significance and significance of value investment [6]. In addition, Li also analyzed Tsingtao Brewery Company based on value investment and put forward some suggestions for investors from the perspective of value investment [7]

Duignan et al. analyzed the 2015 data to remind readers of the risks in the rental industry [8]. The article pointed out that the leasing industry is heavily influenced by oil and gas. When the price of oil and gas falling, the market demand for equipment is weak. In addition, the leasing industry has two defects with large equipment, namely, small demand and poor liquidity. Then, because of poor liquidity, excess large equipment reduces the need for companies to buy new equipment. The article took United Rentals, Inc. as the representative of the whole leasing market. Through analyzing the performance of United Rentals, Inc. in 2015, they thought that the decrease of capital expenditure and time utilization rate gave an evidence that the overall performance of the leasing industry in 2015 was not good enough and may continue to decline. Although the article had effectively pointed out the risks of the leasing industry, it lacked analysis of the changes in the new environment for nowadays investors.

Abhishek et al. proved that one of the trends in the industry was a shift away from ownership of goods to provide multiple access to assets business models [9]. They did a market study to support the ideas, with $81 \%$ of consumers thinking it is cheaper to share goods, while $43 \%$ thinking owning assets feels like a burden. This means that the market model of the sharing economy is more attractive to low-usage consumers. Leasing allows consumers who own assets not only to use the assets when they need them, but also to monetize ownership by renting out unused items to other willing consumers. This article gives many investors from a macro point of view and clearly points out that the lease market has a great space for development.

Other articles mostly analyze the investment value of companies under the condition of stable economic operation, while this paper will consider the influence of
COVID-19. Therefore, the value investment analysis and suggestions for new investors have more practical reference significance. At the same time, the data analyzed in some articles on United Rentals Inc. is too old. The change of the market environment, the company development situation and the regulation of the stock market has a huge difference in present phase. Therefore, this article gives an idea based on the analysis of the latest 5-years data and the new environment background.

This paper mainly analyzes the stock investment value of United Rentals, Inc. After reading and summarizing the research articles on the theory of value investment in different countries, we analyze and study the company in several aspects. First, the development background and the new leasing industry environment of the North American are introduced. Secondly, we will see the operation of United Rentals, Inc. by analyzing its business strategy and financial data, which is the basis for value investment. In addition, there are some valuation methods that are used to help us to do a more detailed analysis of the company's financial data and observe the profitability and value of the company. Then, it is a good way to compare with the other companies in the same industry to judge United Rentals, Inc.'s position value and give the reasons for investors. Finally, based on the above analysis and the actual situation, we will have an overall judgment for the United Rentals, Inc. and give some targeted suggestions that are put forward for investors.

Our findings prove that although under the circumstance of COVID-19, United Rentals, Inc. still outperforms their competitors with fundamentals in the rental market of North America. To be specific, in the aspect of operation, United Rentals, Inc. has a variety of equipments which increase at a stable speed to satisfy the needs of customers and as a result its customer group become larger. At the same time, sales of rental equipment don't alter materially and provide sufficient revenue for United Rentals, Inc. to develop its businesses. On the basis of its financial situation, United Rentals, Inc. net income margin and gross margin are relatively steady in recent years while other companies fail due to COVID-19. Besides, there is a downward trend for liability/asset ratio in United Rentals, Inc. which is not common in other companies in the same industry. In a conclusion, the intrinsic investment value of United Rentals, Inc. is still promising even though confronted with the negative impact of COVID-19.

\section{OPERATING STRATEGY}

2020 is an unpredictable year for all industries and the changes in the social environment in 2020 have a significant impact on United Rentals. 
The Covid-19 appeared at the end of 2019 and continues to adversely affect United Rentals' operations and financial position. At the same time, it has a significant impact on the industrial supply chains and businesses, United Rentals is no exception and the negative effects could be material and practical.

The Covid-19 mainly influences the company's businesses through employees, debt and capital. At first, many employees have to work at home and it reduced the working efficiency greatly. It can be quite hard to meet the customers' demand on time because of lacking enough employees on the ground. Then, to service indebtedness, United Rentals must reduce the funds available for other purposes, including funding working capital, capital expenditures, acquisitions, and as a result it will constrain the flexibility of finance situation. Besides, the scale and scope of the COVID-19 pandemic influence the ability to access funds from financial institutions and capital markets, and causes the slowing capital turnover. Moreover, the situation becomes complicated considering the rental industry of North American.

There are three characterizes in rental industry: customer and supplier groups are not concentrated, strong periodicity, and high liability. At first, we know that the North American equipment rental industry is highly fragmented and competitive. However, compared with other small competitors, United Rentals is the largest equipment rental company in the industry (13\% market share in North America). Therefore, United Rentals have more resources and certain competitive advantages over their smaller competitors including greater purchasing power, the ability to provide better service for customers and so on.

The second industry feature which is widely acknowledged in rental industry is cyclical. United Rentals is an example, their general rental equipment, power and fluid solutions equipment are used in connection with private non-residential construction and industrial activities, which are cyclical in nature. We know that economic slowdowns and decreases will certainly cause weaknesses in the end market, revenues and operating results will also be influenced. When Covid-19 appears, it's getting worse. Therefore, from a long-term perspective, it is normal for equipment rentals gross margins to fluctuate at some intervals. And United Rentals' business belongs to operating lease. So, the rental equipment is generally selected by the leasing company according to the market demand, and then look for the leasing enterprise. When the demand market changes, everything will be different.

The last one of characteristics is that the debt of the whole rental industry is at a high level, which is a common phenomenon.

Based on these characteristics of the rental industry, the leasing industry is easy to be affected by the U.S. government's policies and laws. The outbreak of the COVID-19 has caused serious damage to the American economy. In response, the U.S. government has taken a series of large-scale actions to stabilize and stimulate the economy. For example, Coronavirus Aid, Relief, and Economic Security Act were put forward by congress on March 19, 2020. United Rentals will definitely benefit from the law, they can get financial aid from the government to relieve the burden of debt.

Another policy affecting rental industry is about the environment. United Rentals have operations throughout the United States, which means they must obey state and local regulations. For instance, some laws regulate issues such as wastewater, stormwater, solid and hazardous wastes and materials, and air quality, so they should put environmental protection in an important position. All in all, United Rentals recognizes its social responsibility to protect the environment to respect the law though it will increase burden and cost. To sum up, both policies and laws have had a huge impact on the rental industry.

From now on, we are investigating the performance of United Rentals. At first, as we can be seen from Table 1, the percentage of each business segment barely changed, except for equipment rental decreased $2 \%$ and sales of rental equipment increased $2 \%$.

In addition, equipment rentals decreased $10.3 \%$, which was because COVID-19 began to impact their operations in March 2020. Through February 2020, equipment rentals were up slightly year-over-year. Since March, equipment rentals have decreased year-overyear, primarily due to the impact of COVID-19. Fleet productivity decreased $6.9 \%$, primarily due to the impact of COVID-19 since March when rental volume declined in response to shelter-in-place orders and other markets. In fact, through February, fleet productivity was flat year-over-year and in line with expectations. Sales of rental equipment did not change materially year-over-year. United Rentals has a very stable business growth, which means that the company has sufficient and stable revenue to lay a solid foundation for its expansion. 
Table1 United Rentals' share of revenue from each business segment (\$ in million).

\begin{tabular}{|c|c|c|c|c|c|c|}
\hline Year & \multicolumn{2}{|c|}{2018} & \multicolumn{2}{|c|}{2019} & \multicolumn{2}{|c|}{2020} \\
\hline Equipment Rental & 6,940 & $86 \%$ & 7,964 & $85 \%$ & 7,140 & $84 \%$ \\
\hline $\begin{array}{l}\text { Sales of Rental } \\
\text { Equipment }\end{array}$ & 664 & $8 \%$ & 831 & $9 \%$ & 858 & $10 \%$ \\
\hline $\begin{array}{c}\text { Contractor Supplies } \\
\text { Sales }\end{array}$ & 208 & $1 \%$ & 268 & $1 \%$ & 247 & $1 \%$ \\
\hline $\begin{array}{l}\text { Sales of New } \\
\text { Equipment }\end{array}$ & 91 & $3 \%$ & 104 & $3 \%$ & 98 & $3 \%$ \\
\hline $\begin{array}{l}\text { Service and Other } \\
\text { Revenue }\end{array}$ & 144 & $2 \%$ & 184 & $2 \%$ & 187 & $2 \%$ \\
\hline Total Revenue & 8,047 & $100 \%$ & 9,351 & $100 \%$ & 8,530 & $100 \%$ \\
\hline
\end{tabular}

Source: from United Rentals, Inc. Annual Report [10]

Then, the data showed in Table2, which about the proportion of the company's business, the largest segment is the equipment rental segment. Among this segment, the largest section is $43 \%$ of General Construction and Industrial Equipment. We can see that there wasn't marked change in each section. The change was only in $1 \%$ range, such as fluid solutions equipment and aerial work platforms. This illustrates its stable development and businesses

Table2 United Rentals' specific fleet types

\begin{tabular}{|c|c|c|c|}
\hline Year & $\mathbf{2 0 1 8}$ & $\mathbf{2 0 1 9}$ & $\mathbf{2 0 2 0}$ \\
\hline General construction and industrial equipment & $44 \%$ & $43 \%$ & $43 \%$ \\
\hline Aerial work platforms & $28 \%$ & $28 \%$ & $8 \%$ \\
\hline $\begin{array}{c}\text { General tools and light equipment } \\
\text { Power and HVAC (heating, ventilating and air } \\
\text { condition) equipment }\end{array}$ & $8 \%$ & $8 \%$ & $9 \%$ \\
\hline $\begin{array}{c}\text { Trench safety equipment } \\
\text { Fluid solutions equipment }\end{array}$ & $6 \%$ & $6 \%$ & $6 \%$ \\
\hline
\end{tabular}

Source: from United Rentals, Inc. Annual Report [10].

Besides, whether the company has stable suppliers and customers is also an important factor for investors to consider. The five-year statistics in the annual report show that the percent of the largest supplier and top10 supplies are decreasing. There may be several reasons. To begin with, their strategic approach related to their supplier is to maintain the minimum number of suppliers per category of equipment that can satisfy our anticipated volume and business requirements. Under the guide of this strategy, they indeed achieved significant cost savings through their centralization of equipment and non-equipment purchases, but they 
depend on and are exposed to the credit risk of a group of key suppliers. They may build a set of standards to evaluate these suppliers' conditions and try to make the best choice, the risks are still existed in the failures for suppliers to perform the contracts due to the difficulties, such as finical problems, insolvency. Besides, their competitors include equipment vendors and dealers who both sell and rent equipment directly to customers. Compare with selling equipment to them, these vendors and dealers have a price advantage. They are not only the cooperators but also competitions. Also, when United Rentals progressively became the largest part of rental equipment industry in North America, they have luxurious choices to maximize their profit and minimize their cost in each part without being dependent on the major suppliers. Thus, they have to gradually reduce the major suppliers and distribute their ways to other channels and suppliers. The gradual reductions of the largest supplier and top 10 suppliers show the result of the further development in United Rentals.

Moreover, the largest customer percent of total revenues in United Rental, Inc. doesn't change, which is $1 \%$. At the same time, the top 10 customers percent of total revenues in the company decrease from $6 \%$ to $4 \%$. It is not a bad thing because its key account percent of equipment rental revenue shows an increasing trend from 2016 to 2020 , which is $70 \%, 69 \%, 71 \%, 72 \%$, and $74 \%$. The increase of key customers in equipment rental revenue reflects there are more customers designated as key customers compared to the previous year. This means that the key customer groups are increase and the company has a broader and more stable sales channel. Also, through reading United Rentals' annual reports from 2016 to 2020, the company's share of the North American market increased from $10.1 \%$ in 2016 to $13 \%$ in 2020 , which supports the idea that the company has more customers and wide sales channels.

Except for supply and sale channels, we also need to see if the company is constantly innovating. For leasing companies, we have to pay attention to whether there are new types of equipment. In Table 3 the variety of equipment in United Rentals has increased every year, which has a positive impact on the development of the business. In addition, United Rentals sold more and more used rental equipment to reduce repair and maintenance costs, and they also buy a lot of new equipment to replace used equipment to meet customer needs each year. Also, the growth rate of new equipment purchases by the company slowed a decrease of $7.8 \%$ in 2020 . We think because of the influence of COVID-19, the company chose to reduce the cost of purchasing new equipment while maintaining the revenue from the sale of used equipment. The increase of the variety of equipment helps United Rental, Inc. to better meet the needs of customers. And under the adverse effects of COVID-19, the company has chosen to reduce costs by purchasing fewer new equipment.

Table3 Equipment capacity of the company (\$ in million).

\begin{tabular}{|c|c|c|c|c|c|}
\hline Year & $\mathbf{2 0 1 6}$ & $\mathbf{2 0 1 7}$ & $\mathbf{2 0 1 8}$ & $\mathbf{2 0 1 9}$ & $\mathbf{2 0 2 0}$ \\
\hline Types of equipment & 3,200 & 3,400 & 3,800 & 4,000 & 4,000 \\
\hline Sales of rental equipment & $\$ 496$ & $\$ 550$ & $\$ 664$ & $\$ 831$ & $\$ 858$ \\
\hline Growth rate of sales & N/A & $10.9 \%$ & $20.7 \%$ & $25.2 \%$ & $3.2 \%$ \\
\hline Sales of new equipment & $\$ 144$ & $\$ 178$ & $\$ 208$ & $\$ 268$ & $\$ 247$ \\
\hline Growth rate of sales & N/A & $23.6 \%$ & $16.9 \%$ & $28.8 \%$ & $-7.8 \%$ \\
\hline
\end{tabular}

Source: from United Rentals, Inc. Annual Report [10].

\section{FINANCIAL ANALYSIS IN UNITED RENTALS}

After analyzing the United Rentals business operations, we will discuss the performance of the financial data from 2016 to 2020 .
The United Rentals' sales growth rate has been above $15 \%$ from 2016 to 2019 which shows in Table 4. However, the company was severely impacted by COVID-19 in 2020 and revenue showed a significant decrease to $-8.8 \%$. Also, decrease in revenue in 2020 resulted in volume declines in response to shelter-inplace orders and other market restrictions. 
Table4 United Rental's sales and operating income (\$ in million).

\begin{tabular}{|c|c|c|c|c|c|}
\hline Year & $\mathbf{2 0 1 6}$ & $\mathbf{2 0 1 7}$ & $\mathbf{2 0 1 8}$ & $\mathbf{2 0 1 9}$ & $\mathbf{2 0 2 0}$ \\
\hline Total Revenue & $\$ 5,762$ & $\$ 6,641$ & $\$ 8,047$ & $\$ 9,351$ & $\$ 8,530$ \\
\hline Net Income & $\$ 566$ & $\$ 1,346$ & $\$ 1,096$ & $\$ 1,174$ & $\$ 890$ \\
\hline Sales Growth Rate* & N/A & $15.3 \%$ & $21.2 \%$ & $16.2 \%$ & $-8.8 \%$ \\
\hline
\end{tabular}

Source: from United Rentals, Inc. Annual Report [10].

*Sales Growth Rate $=$ (The total revenue of the previous year - the total revenue of this year $) /$ the total revenue of the previous year.

Then, we can estimate the value of the company. Generally speaking, if $\mathrm{P} / \mathrm{E}$ ranges from $5-15$, we can say the company is a value stock. As can be seen from the data in Table 5, United Rentals' $\mathrm{P} / \mathrm{E}$ ratio basically stayed within this range. However, data were higher 15 in 2020 because of the adverse impact of COVID-19 in 2020.

$\mathrm{EV} / \mathrm{sales}$ are also a measure to weigh the profitability of a company. The higher the measure is, the more profitable a company is. However, the statistic should be lower than 10 . We can see the sheet above. United Rentals, Inc. kept over 2 in every year, even in 2017 the number reached up to 3 . In summary, the 2020 decline in revenue includes the impact of the COVID19 , which resulted in volume declines in response to shelter-in-place orders and other market restrictions.

In addition, even with the impact of COVID-19, United Rental continues to achieve increasing market value and Enterprise value.

Table5 The profitability and value of United Rental, Inc. (\$ in million).

\begin{tabular}{|c|c|c|c|c|c|}
\hline Year & 2016 & 2017 & 2018 & 2019 & 2020 \\
\hline P/E Ratio & 16.27 & 10.81 & 7.73 & 10.99 & 18.93 \\
\hline EV/Sales & 2.69 & 3.47 & 2.32 & 2.38 & 2.8 \\
\hline Market Value & $\$ 8,892.16$ & $\$ 14,520.21$ & $\$ 8,189.38$ & $\$ 12,401.35$ & $\$ 16,609.41$ \\
\hline Enterprise Value & $\$ 15,500.16$ & $\$ 23,053.21$ & $\$ 18,665.38$ & $\$ 22,263.35$ & $\$ 23,851.41$ \\
\hline Gross Margin* & $41.7 \%$ & $41.7 \%$ & $41.8 \%$ & $39.2 \%$ & $37.3 \%$ \\
\hline Asset Turnover** & $0.5 \mathrm{x}$ & $0.4 \mathrm{x}$ & $0.4 \mathrm{x}$ & $0.5 \mathrm{x}$ & $0.5 \mathrm{x}$ \\
\hline Net Income Margin $* * *$ & $9.8 \%$ & $20.3 \%$ & $13.6 \%$ & $12.6 \%$ & $10.4 \%$ \\
\hline Return of Equity $* * * * *$ & $20 \%$ & $18.4 \%$ & $18.6 \%$ & $19.3 \%$ & $17.8 \%$ \\
\hline Earning Per Share & 6.49 & 15.91 & 13.26 & 15.18 & 12.24 \\
\hline Liability/Asset Ratio & $86.2 \%$ & $70.3 \%$ & $81.2 \%$ & $79.8 \%$ & $74.5 \%$ \\
\hline
\end{tabular}

Source: from United Rentals, Inc. Annual Report [10].

${ }^{*}$ Gross Margin= $($ Revenue-Cost of good sold $) /$ Revenue

**Asset Turnover= Revenue/Asset

*** Net Income Margin=Net Income/Revenue

*****Profitability $=$ Gross Margin x Asset Turnover

After discussing the value of United Rentals, it is important for investors to analyze the profitability of the company. According to Figure 1, we calculated how much net profit obtained from each dollar which is presented in Figure 1. We can see that in 2016, the United Rental's net income margin was only $9.82 \%$, but it experienced an unusual growth in 2017 to $20.27 \%$. In 2018, the company's net income margin returned to normal, and in the following two years, although there was a small decrease, United Rental's net income margin still remained above $10 \%$. We described the results of the net income margin trend, which show United Rental had a stable net income margin. The reason for United Rental's net income margin rapid growth in 2017 is the United States published The Tax Act. The changes in tax law cause United Rental's net 
income increases for the year ended in 2017 due to a one-time revaluation of the net deferred tax liability after the U.S. federal tax rate was reduced from $35 \%$ to $21 \%$ and the United Rental's continuing foreign exchange earnings and profits partially offset the impact of the one-time shift tax will pay over in eight years. Even though we saw that the United Rental's net income margin increased abnormally in 2017, compared with 2016, net income margin has been increased to more than $10 \%$ to a large extent. COVID-19 has greatly affected the company's operation in 2020, but United Rental's net income margin remains stable at more than $10 \%$. Even though United Rental's net income margin and gross profit margin showed a little bit declined, but overall, the performance of profitability was relatively stable. While the company has a stable return on equity, relatively high earning per share is also a highlight of investment.

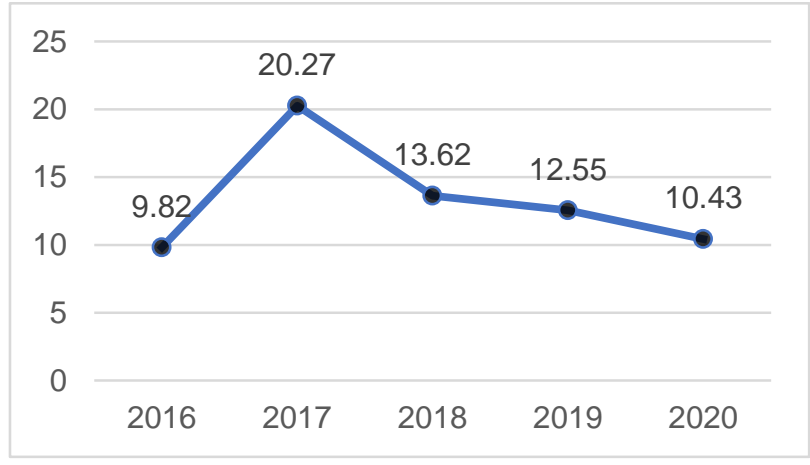

Figure 1. United Rentals' Net Income Margin From 2016 to 2020 (Present in \%)

Source: from United Rental, Inc. Annual Report [10].

Then, this is schematically shown in Figure 2. which calculated the company' s Gross Margin. From 2016 to 2018, the United Rental' s gross profit margin was stable and higher than $41 \%$, but it showed a fall about $2 \%$ a year in 2019 and 2020. The company did not perform well in the past two years, but before that it had stable and high gross profit margins. The 2019 decline was influenced by the acquisition of two companies in 2018 - BlueLine and BakerCorp. On the one hand, the equipment depreciation rate of the two acquired companies increased by $19.7 \%$, and it exceeded the equipment rentals growth of $14.8 \%$. On the other hand, operating costs for the maintenance and reset of equipment make United Rentals have more expenditure fee. In addition, because CPVID-19 began to affect the company's operations, total revenues in 2020 decreased $8.8 \%$ compared with 2019 and cause a declining trend of gross margin. However, even though the company's gross margin declined in the last two years, we can confident that the future is on the rise for two reasons. First of all, after COVID-19, we believe the world economy will recover and the United Rental's business will work again. Secondly, as a company that grew through acquisition, United Rentals can be expected to be able to solve the problems existing in the acquisition and increase the growth of gross profit margin in the future.

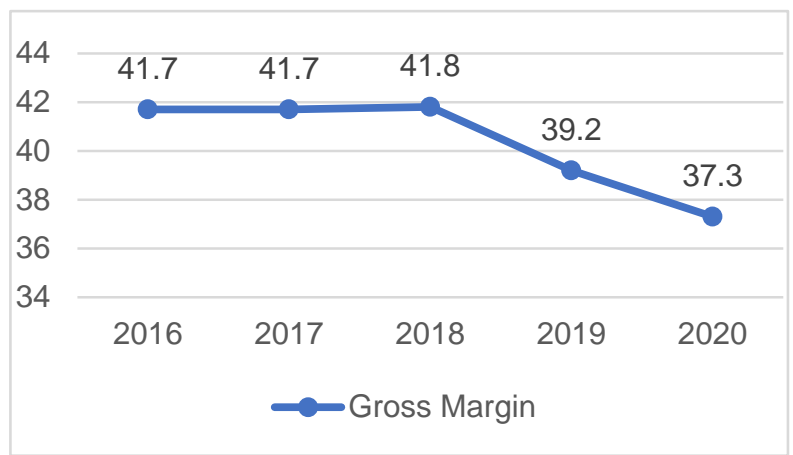

Figure 2. United Rentals' Gross Margin From 2016 to 2020 (Present in \%)

Source: from United Rental, Inc. Annual Report [10].

Next, we can see the range of values used in return on equity are listed in Table 2. In general, return on equity of $15-20 \%$ is considered a company that have good profitability. Therefore, we can believe that even under the adverse effects of COVID-19 in 2020, United Rentals is a value stock with stable profitability, and its return on equity is stable and still higher than $17 \%$. Therefore, even though United Rental's net income margin and gross profit margin showed a little bit declined, but overall, the performance of profitability was relatively stable. In addition, while the company has a stable return on equity, relatively high earning per share is also a highlight of investment.

Last but not least, Table 5 summarizes the range of parameters used in liability. Even though it still at a high level, there was a downward trend for liability/asset ratio. It is very normal in the rental industry. There are two reasons for United Rentals. have a high liability/asset ratio. At first, in the recent 3 years, United Rentals, Inc. completed several acquisitions, like NES, Bakercrop and BlueLine. These companies' assets and liabilities will definitely influence the structure of Asset and Liability of United Rentals Therefore, if new debt is added to their existing and future subsidiaries' current debt, the related risks that they now face could intensify and they may not be able to meet all of their debt obligations. Besides, as the result of COVID-19, some of their customers may have liquidity issues and ultimately may not be able to meet the terms of their rental agreements with URI. Under these circumstances, their credit losses could increase above historical levels and their financial condition would be adversely affected. And United Rentals situation would worsen if COVID-19 and the economic situation continue to deteriorate. Liabilities are increasing with the development of the company' s business, but there was a downward trend for liability/asset ratio. 


\section{FINANCIAL ANALYSIS COMPARED WITH OTHER COMPANIES}

We choose three major companies in this industry. Even if there are other companies that belong to rental industry, their major business segments are not the equipment rental. Thus, if we take these other companies into consideration, the data can' t reflect the true condition. Therefore, we just use these three companies to compute the industrial averages of gross margin, net income margin, etc., comparing them with United Rentals.

In combination with Table 5 and 6, compared with the average of these three companies in three years, we can see that United Rentals' data is outperformed. In three years, its revenue was over $\$ 8,000$ million, and far above the average and maximum in the industry which were just $\$ 97.6$ million and $\$ 1,999$ million. Besides, the gross margin in 2020 was $41.8 \%$ higher than the average $36.3 \%$. Also, net income margin kept over $10 \%$ and EPS was higher than 10 . They were all way above the average. They all illustrate that United Rentals has a good development and has huge potential. United Rentals' revenue, gross margins, net income margins and earning per share are all higher than industry averages.

Table6 Compared profit quantity with 3 companies in three years (\$ in million)

\begin{tabular}{|c|c|c|c|c|c|c|c|c|c|c|c|c|}
\hline & \multicolumn{3}{|c|}{ Revenue } & \multicolumn{3}{|c|}{ Gross Margin } & \multicolumn{3}{|c|}{ Net Income Margin } & \multicolumn{3}{|c|}{ Earning Per Share } \\
\hline Year & 2018 & 2019 & 2020 & 2018 & 2019 & 2020 & 2018 & 2019 & 2020 & 2018 & 2019 & 2020 \\
\hline $\begin{array}{c}\text { Willscot } \\
\text { Corporation }\end{array}$ & $\$ 75.1$ & $\$ 106.4$ & $\$ 136.8$ & $38.5 \%$ & $38.9 \%$ & $48.3 \%$ & $-6.5 \%$ & $-1.1 \%$ & $5.2 \%$ & -0.59 & -0.1 & 0.42 \\
\hline $\begin{array}{l}\text { Herc Holding, } \\
\text { Inc. }\end{array}$ & $\$ 1,976.7$ & $\$ 1,999.0$ & $\$ 1,781.3$ & $26.2 \%$ & $27.1 \%$ & $26.1 \%$ & $3.5 \%$ & $2.4 \%$ & $4.1 \%$ & 2.43 & 1.66 & 2.51 \\
\hline $\begin{array}{l}\text { Hawaiiian } \\
\text { Electric, Inc. }\end{array}$ & $\$ 286.1$ & $\$ 287.4$ & $\$ 258.0$ & $35.4 \%$ & $27 \%$ & $34.4 \%$ & $6.2 \%$ & $6.5 \%$ & $-2.8 \%$ & 2.15 & 2.43 & -0.91 \\
\hline Average & $\$ 779.3$ & $\$ 797.6$ & $\$ 725.4$ & $33.4 \%$ & $31.0 \%$ & $36.3 \%$ & $1.1 \%$ & $2.6 \%$ & $2.2 \%$ & 1.33 & 1.33 & 0.7 \\
\hline
\end{tabular}

Source: from United Rental, Inc. Annual Report [10], Willscort Corporation [11], Herc Holding, Inc[12], Hawaiian Electric,Inc [13]

United Rentals' asset turnover was about the average. It shows that United Rentals makes good use of its assets and can keep pace with the industry.

Also, we computed some data and measure whether they have value. Before analyzing United Rentals, its $\mathrm{P} / \mathrm{E}$ ratio was ranged from 5 to 15 . However, from the perspective of these three companies, their number were all higher than 15 in each year. We can get a conclusion that a high $\mathrm{P} / \mathrm{E}$ ratio is the common condition in this industry. Thus, in 2020 and 2016, the $\mathrm{P} / \mathrm{E}$ ratios in United Rentals, were a little higher than 15 , they were still lower than the average. Therefore, we consider it must be a value stock. The average of these three companies' EV/Sales was about 1 and the maximum was 2.23. We can compare data with Table 5 and 7. United Rentals kept over 2 in every year, even in 2017 the number reached up to 3. Its EV/Sales were the best, which demonstrates that it has good potential value and strong development ability. Compared with the other companies with a higher return on equity, United Rentals not only have great revenue, but also show good above-average profitability. 
Table.7 Compared profitability with 3 companies in three years

\begin{tabular}{|c|c|c|c|c|c|c|c|c|c|c|c|c|}
\hline & \multicolumn{3}{|c|}{ Asset Turnover } & \multicolumn{3}{|c|}{ P/E Ratio } & \multicolumn{3}{|c|}{ EV/Sales } & \multicolumn{3}{|c|}{ ROE } \\
\hline Year & 2018 & 2019 & 2020 & 2018 & 2019 & 2020 & 2018 & 2019 & 2020 & 2018 & 2019 & 2020 \\
\hline $\begin{array}{c}\text { Willscot } \\
\text { Corporation }\end{array}$ & $0.3 x$ & $0.4 x$ & $0.3 x$ & N/A* & N/A* & 9.73 & 2.23 & 1.53 & 1.79 & $12.3 \%$ & $14.3 \%$ & $11.8 \%$ \\
\hline Herc Holding, Inc. & $0.6 \mathrm{x}$ & $0.5 \mathrm{x}$ & $0.5 \mathrm{x}$ & 10.70 & 30.02 & 26.25 & 1.45 & 1.70 & 2.01 & $14.4 \%$ & $14.2 \%$ & $12.9 \%$ \\
\hline $\begin{array}{l}\text { Hawaiian Electric, } \\
\text { Inc. }\end{array}$ & $0.7 \mathrm{x}$ & $0.7 x$ & $0.6 \mathrm{x}$ & 19.79 & 23.43 & 19.55 & 0.02 & 0.02 & 0.02 & $25.4 \%$ & $25.3 \%$ & $20.3 \%$ \\
\hline Average & $0.5 x$ & $0.5 \mathrm{x}$ & $0.5 \mathrm{x}$ & 15.25 & 26.73 & 18.51 & 1.23 & 1.08 & 1.27 & $17.7 \%$ & $18.3 \%$ & $15.7 \%$ \\
\hline
\end{tabular}

Source: from United Rental, Inc. Annual Report [10], Willscort Corporation [11], Herc Holding, Inc[12], Hawaiian Electric,Inc [13].

*The P/E of Willscot Corporation from 2018-2019 are negative numbers. They are meaningless, so it is unnecessary to compute its average and median.

According to Table 5 and 8, combining data from these three companies, it shows a phenomenon in this industry, that is, highly leveraged. The reason is as a rental company, they need a wide array of equipment to be rented and purchased. They must invest a huge amount of finance on purchasing new and second-hand equipments or acquit other companies to acquire their business and equipments to expend their bunnies scale and market share. At the same time, they have to maintain their daily sales and operating. Thus, they have a series of long-term and short-term debts. The same is true of United Rentals. The United Rentals' liabilities/assets ratio was a little higher than the average in 2019 and 2018. The reason is, just said before, that it completed several acquisitions in three years. These acquitted companies also have a lot of debt to be reimbursed. Therefore, it makes United Rentals' ratio higher than the average. Risk warning: United Rentals' liability/asset ratio was slightly above average for 2018 and 2019 due to acquisitions of other companies.

Table8 Compared liability with 3 companies in three years

\begin{tabular}{|c|c|c|c|c|c|c|}
\hline & \multicolumn{3}{|c|}{ Liability/assets Ratio } & \multicolumn{2}{c|}{ Debt to Equity Ratio } \\
\hline Year & $\mathbf{2 0 1 8}$ & $\mathbf{2 0 1 9}$ & $\mathbf{2 0 2 0}$ & $\mathbf{2 0 1 8}$ & $\mathbf{2 0 1 9}$ & $\mathbf{2 0 2 0}$ \\
\hline $\begin{array}{c}\text { Willscot } \\
\text { Corporation }\end{array}$ & $74.5 \%$ & $75.5 \%$ & $61.6 \%$ & $321.3 \%$ & $339.7 \%$ & $160.2 \%$ \\
\hline $\begin{array}{c}\text { Herc Holding, } \\
\text { Inc. }\end{array}$ & $84.1 \%$ & $83.1 \%$ & $79.3 \%$ & $530.4 \%$ & $492.4 \%$ & $383.6 \%$ \\
\hline $\begin{array}{c}\text { Hawaiian } \\
\text { Electric, Inc. }\end{array}$ & $83.2 \%$ & $83.2 \%$ & $84.2 \%$ & $504.4 \%$ & $501.3 \%$ & $540.4 \%$ \\
\hline \begin{tabular}{c} 
Average \\
\hline
\end{tabular} & $80.6 \%$ & $80.6 \%$ & $75.0 \%$ & $452.0 \%$ & $444.5 \%$ & $361.4 \%$ \\
\hline
\end{tabular}

Source: from United Rental, Inc. Annual Report [10], Willscort Corporation [11], Herc Holding, Inc[12], Hawaiian Electric,Inc [13].

Above all, compared with three other major companies in the rental industry with earning rate, profitability and liability, United Rentals takes the lead on the whole. Although it is not exceedingly superior to other companies in every index, it still has the dominant position in the rental market of North America (since the market share is as high as $11 \%$ ) even faced with the risk of Covid-19. 


\section{CONCLUSION}

The paper shows that faced with COVID-19, United Rentals outperforms well both in operating and financial aspects. In other words, United Rentals is a promising stock with great investment value because it grows fast, is cheap, and has a high expected return, and it still has a good price appreciation in the rental market. As the largest rental company of North American, it still has the potential for future development, and its stable fundamentals strongly show that investment value is quite high.

These findings may provide references for investors who are willing to get intrinsic value from the rental market under the impact of COVID-19, especially for those value investors. Besides, our results will make people reconsider the importance of value investment strategy. In addition, our empirical evidences are beneficial to policy decision makers to realize the extent that covid-19 affects the real economy.

However, in the selection of financial data, we select more targeted and representative data for analysis instead of choosing all of the financial data for a complete analysis, so the data scale is relatively limited. Future research is needed to collect more comprehensive data to provide high-quality investment suggestions.

\section{REFERENCES}

[1] Joint Research and Development Center for Leasing. Report on the development of financial leasing industry in the first half of 2020. North China finance, (10), 2020, pp.30-38. Available at: https://kns.cnki.net/kcms/detail/detail.aspx?dbcode $=$ CJFD\&dbname $=$ CJFDLAST2020\& filename $=$ JRS C202010004\&v=vksgiGx5ByMgS4CjYZ71kMNX yb7ysOPKCxsNfJcVY7yTSRGJqg0n68ts2sht7uJz

[2] S.Q. Sun. Exploration of construction machinery leasing in the United States.[J]. Construction mechanization, 2008, 15 (03), 57-58 + 6. Available at:

https://kns.cnki.net/kcms/detail/detail.aspx?dbcode $=$ CJFD\&dbname $=$ CJFD2008\&filename $=$ JZJH2008 03046\&v=Aadx\%25mmd2ByMBrccUgVhLHWtE 7V91vGamnl02zJVdRBaMrJaJxg4\%25mmd2Bd5t 4poTgCpolVYsj

[3] B.H. Li. Financial operation of operating leasing companies: a comparative study based on United Rentals, Inc. and X leasing company. [C]. East China University of science and technology, 2014.

[4] B. Graham, D. Dodd. Securities analysis. [M]. China Renmin University Press, 2014.

[5] J. Berk and P. Demarzo. Corporate Finance.[M] Personal education, 2017, pp.56-82.

[6] J.B. Sun, P.Z. Wang. A review of common stock pricing models of listed companies from the perspective of value investment. [J]. Frontier, (20), 2011, pp.106-109. Available at:

https://kns.cnki.net/kcms/detail/detail.aspx?dbcode $=\mathrm{CJFD} \& \mathrm{dbname}=\mathrm{CJFD} 2011 \&$ filename $=\mathrm{QAYA} 20$ $1120030 \& \mathrm{v}=15 \mathrm{NFkXE} \% 25 \mathrm{mmd} 2 \mathrm{FGyVzM} 2 \mathrm{ph} 7 \mathrm{rtg}$ qmM\%25mmd2B94sjAPcSCtPnBSEwV62KABY GZPiI12ZHtj3IUrKG

[7] M. Li. Analysis on the stock investment value of Listed Companies -- Taking Tsingtao beer as an example [C]. Hefei University of technology, 2020.Available at:

https://kns.cnki.net/kcms/detail/detail.aspx?dbcode $=\mathrm{CMFD} \&$ dbname $=\mathrm{CMFD} 202101 \&$ filename $=1020$ 420919.nh\&v=7cC3tVojWf1P\%25mmd2FEEvzf0 91JT7sxR6sy\%25mmd2FtGVSvX1zDfXiB07qBE9 ng0scH4YQ7bstD

[8] A, Duignan, M. Conlon, K. Li, C. Wong, \& T. Sano. Global Machinery. JP Morgan Chase, 2016, pp.25. Available at:

https://robo.datayes.com/v1.5/information/external Report/1725603

[9] V. Abhishek, J. Guajardo, \& Z. Zhang. Business Models in the Sharing Economy: Manufacturing Durable Goods in the Presence of Peer-to-Peer Rental Markets. Microeconomics: Production, 2020, pp.2. Available at:

https://poseidon01.ssrn.com/delivery.php?ID=2490 00000081125019114087114086084065040082022 00203901606610902410011609010900911409512 20310180040120450980030171081161231091140 51027045019081114107114081102011091126040 04604108108407009011708411307006909908507 20160280080920200820681100281070930670740 $01 \&$ EXT $=$ pdf $\&$ INDEX $=$ TRUE

[10] The Annual Report of United Rentals, Inc. Available at:

https://www.sec.gov/edgar/browse/?CIK=1067701 \&owner=exclude

[11] The Annual Report of Willscort Corporation. Available at:

https://www.sec.gov/edgar/browse/?CIK=1647088 \&owner=exclude

[12] The Annual Report of Herc Holding, Inc. Available at:

https://www.sec.gov/edgar/browse/?CIK=1364479 \&owner=exclude

[13] The Annual Report of Hawaiian Electric, Inc.Available at: https://www.sec.gov/edgar/browse/?CIK=354707\& owner=exclude 